\title{
Gastric acid and pancreatic polypeptide responses to modified sham feeding. Effects of truncal and parietal cell vagotomy
}

\author{
S J KONTUREK, T POPIELA, M SŁOWIACZEK, AND W BIELAŃSKI \\ From the Institute of Surgery, Medical Academy, Kraków, Poland
}

SUMMARY The effects of truncal vagotomy and parietal cell vagotomy on gastric acid secretion and plasma gastrin and pancreatic polypeptide release were studied in 28 duodenal ulcer patients under basal conditions and after modified sham feeding and infusion of pentagastrin $(2 \mu \mathrm{g} / \mathrm{kg} / \mathrm{h})$. Before vagotomy gastric acid output in response to modified sham feeding was significantly higher than basal acid secretion in all subjects tested and reached about $45 \%$ of the pentagastrin maximum. No difference in the increase in acid response, or in the pancreatic polypeptide response to modified sham feeding was found between patients with high and low basal secretion. Plasma gastrin concentration was unaltered by modified sham feeding before and after truncal vagotomy or parietal cell vagotomy, although after vagotomy it tended to reach higher values than before this procedure. After truncal vagotomy, basal pancreatic polypeptide concentration was decreased and modified sham feeding-induced pancreatic polypeptide increment was completely eliminated. Four weeks after parietal cell vagotomy, the modified sham feeding-induced increment in plasma pancreatic polypeptide was significantly decreased and observed only in seven of 12 patients. Four to five years after parietal cell vagotomy all subjects responded to modified sham feeding with pancreatic polypeptide increment similar to that before vagotomy and in three of 12 patients acid response to modified sham feeding was seen. This study indicates that (1) truncal vagotomy eliminates gastric acid and plasma pancreatic polypeptide responses to vagal excitation while parietal cell vagotomy abolishes gastric acid response and reduces temporarily the pancreatic polypeptide response to modified sham feeding (possibly because of transient impairment of the vagal innervation of the pancreas) (2) A high ratio of basal to maximal acid output in non-operated duodenal ulcer patients is not associated with a low acid response to modified sham feeding, nor with a high pancreatic polypeptide concentration, and (3) Restitution of the pancreatic polypeptide response to modified sham feeding five years after parietal cell vagotomy does not indicate ineffective denervation of the parietal cells.

Cephalic vagal excitation induced by sham feeding results in a potent gastric secretory stimulation accompanied by a rapid increase in plasma concentration of pancreatic polypeptide seen in animals ${ }^{1}$ and in man. ${ }^{2-6}$ Duodenal ulcer patients with increased basal gastric acid secretion, presumably caused by

Address for correspondence: Prof Dr S J Konturek, 31-531 Kraków, ul Grzegórzecka 16, Poland.

Received for publication 11 July 1986 high vagal activity, were reported to secrete little or no additional acid and to release less pancreatic polypeptide in response to vagal stimulation by sham feeding. ${ }^{67}$ The spontaneous release of pancreatic polypeptide appears to be regulated by tonic vagal cholinergic activity and the plasma pancreatic polypeptide concentration fluctuates synchronically with gastric acid secretion. ${ }^{x}$ Although the secretion of gastric acid and the release of pancreatic polypeptide are not related, the plasma pancreatic polypeptide 
determination was proposed as an independent indicator of vagal activity of the oxyntic glands. ${ }^{59}$

Previous studies showed that truncal vagotomy permanently abolished the vagally stimulated gastric acid secretion and pancreatic polypeptide release. ${ }^{410-12}$ Selective gastric vagotomy also was found to reduce both gastric acid and the pancreatic polypeptide responses to insulin hypoglycaemia ${ }^{13}$ but little information is available regarding the effect of the parietal cell vagotomy on both gastric acid and pancreatic polypeptide secretion in man. ${ }^{813}$

This study was undertaken to compare the effects of truncal vagotomy and parietal cell vagotomy on gastric acid and plasma gastrin and pancreatic polypeptide responses to physiological vagal stimulation induced by modified sham feeding in duodenal ulcer patients.

\section{Methods}

\section{PATIENTS}

Twenty eight male patients aged 42 years (range 17-60 years) were studied who had endoscopically proven duodenal ulcer for at least five years. In most cases perforation or haemorrhage were recorded before the submission to surgery. Sixteen patients, aged 40 years (range 17-60 years) had a truncal vagotomy and 12 aged 36 years (range $22-45$ years) had parietal cell vagotomy. In all patients secretory tests were done before surgery and twice after surgery; once four to five weeks after parietal cell vagotomy and again four to five years later. The study was approved by a Human Research Review Committee and informed consent was obtained from each subject. The patients received no anticholinergics or $\mathrm{H}_{2}$-blockers for at least five days before the secretory studies were started.

In all patients, gastric acid was examined under basal conditions (BAO) and after stimulation by modified sham feeding (SAO) using the 'chew and spit' technique and after pentagastrin infusion (PAO) as described before. ${ }^{45}$ Gastric acid outputs were measured in each juice aliquot collected 60 minutes before and 180 minutes after modified sham feeding and during 90 minutes of pentagastrin (2 $\mu \mathrm{g} / \mathrm{kg} / \mathrm{h}$ ) infusion. The values of BAO, SAO, and PAO were expressed as acid outputs per 30 minutes. Basal acid output was calculated from the four 15 minute outputs before modified sham feeding. Stimulated acid output and PAO were calculated from the sum of two consecutive highest outputs after modified sham feeding, or pentagastrin infusion, respectively. In all these subjects, vagotomy was complete as judged by insulin tests carried out 10 days after the operation. The dose of insulin was $\mathbf{0 \cdot 2}$ $\mathrm{U} / \mathrm{kg}$ injected intravenously and the response was considered to be 'positive' or 'negative' by multiple criteria. ${ }^{14}$

In all tests except those with pentagastrin, venous blood samples were obtained from a peripheral vein at 15 minutes and just before the modified sham feeding and then $7 \cdot 5,15,30,45,75$, and 105 minutes after the start of the modified sham feeding. Blood samples were collected in chilled tubes with 10 units heparin and $400 \mathrm{KIU}$ aprotonin (Trasylol) and centrifuged and the plasma frozen within 15 minutes of sampling. Serum gastrin and pancreatic polypeptide were measured by radioimmunoassay. Antibody to gastrin (rabbit antiserum 4562) was kindly provided by Professor J F Rehfeld at Aarhus, Denmark and was used to measure plasma gastrin concentration as described. ${ }^{45}$ Antibody to human pancreatic polypeptide (rabbit antiserum 146-10), kindly supplied by Dr R A Chance, Lilly Research Lab, Indianapolis, was used at final dilution of 1:1250000 to determine pancreatic polypeptide concentration as described before. ${ }^{5}$ Both gastrin and pancreatic polypeptide were labelled by an iodo-gen method $^{15}$ and the tracer was purified on SEP-PAK cartrige $\mathrm{C}_{18}$ column 16 .

Activated charcoal was used as a method of separation. Synthetic human heptadecapeptide gastrin (G-17-I) and highly purified synthetic human pancreatic polypeptide were used as standards in the above radioimmunoassays. The detection limit was about $1.5 \mathrm{pM}$ for plasma gastrin and $2 \mathrm{pM}$ for plasma pancreatic polypeptide.

\section{STATISTICAL ANALYSIS}

Results are expressed as the means \pm SEM. Student's $t$ test was used to determine the significance of difference between the means, with differences giving a $\mathrm{p}$ value of less than $0 \cdot 05$ being considered significant.

\section{Results}

EFFECTS OFTRUNCAL VAGOTOMY AND PARIETAL CELL VAGOTOMY ON BASAL AND MODIFIED SHAM FEEDING AND PENTAGASTRIN INDUCED ACID SECRETION

Mean gastric acid outputs under basal conditions and after modified sham feeding in 16 duodenal ulcer patients before and after truncal vagotomy are shown in Figure 1. Before truncal vagotomy, mean peak acid response to modified sham feeding amounted to about $43 \%$ of the pentagastrin maximum. After the truncal vagotomy, basal acid output was reduced significantly by about $68 \%$. Modified sham feeding in patients with truncal vagotomy failed to cause any change in acid output while pentagastrin infusion resulted in about $45 \%$ smaller mean peak acid output 


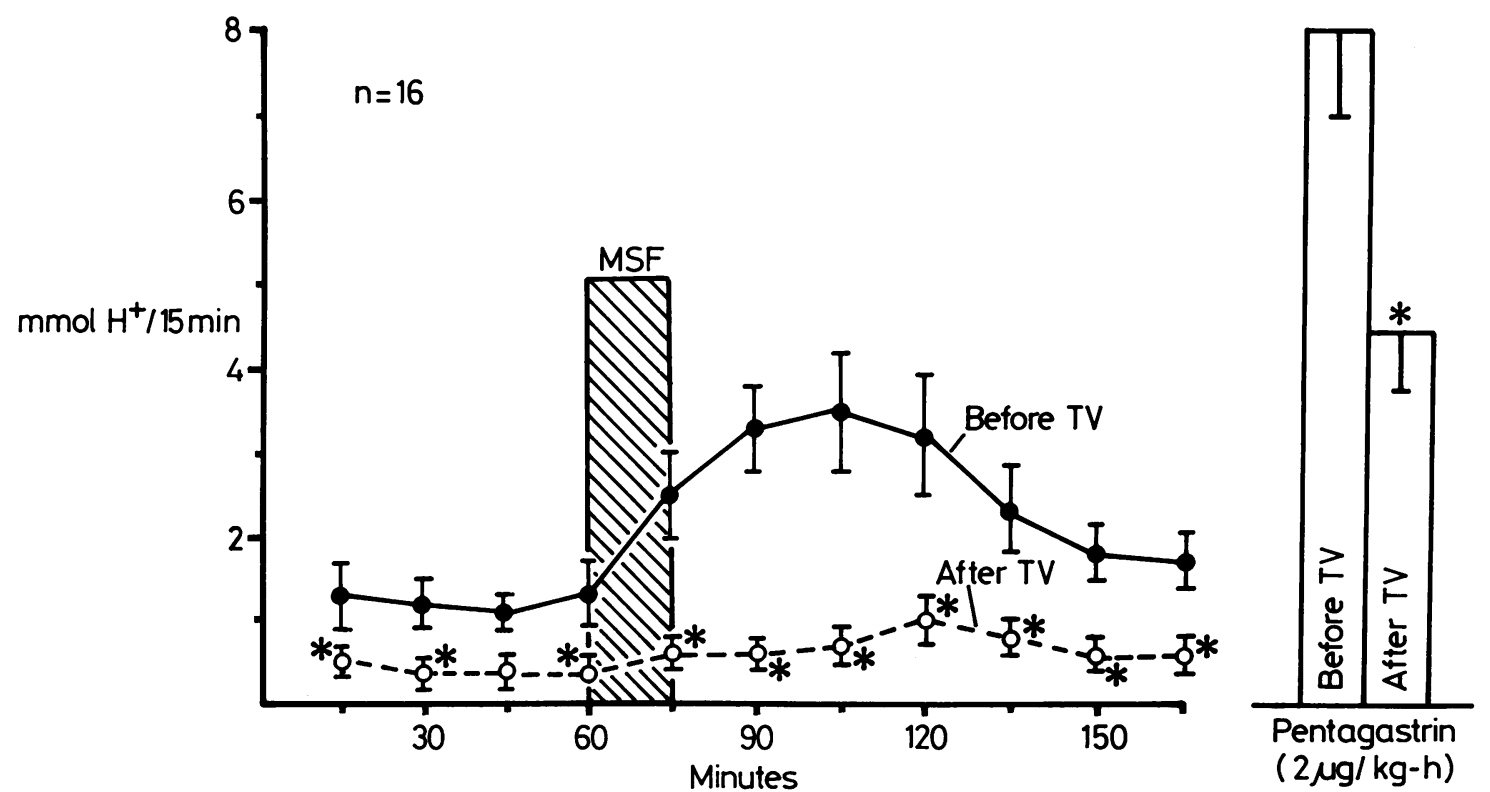

Fig. 1 Gastric acid outputs under basal conditions and after modified sham feeding (MSF) (performed during 15 min) and after infusion of pentagastrin $(2 \mu \mathrm{g} / \mathrm{kg} / \mathrm{h})$ in 16 duodenal ulcer patients before and after truncal vagotomy (TV). Mean $\pm S E M$ of 16 tests on 16 patients. ${ }^{*}$ indicate significant $(p<0.05)$ decrease below the control values obtained before vagotomy.

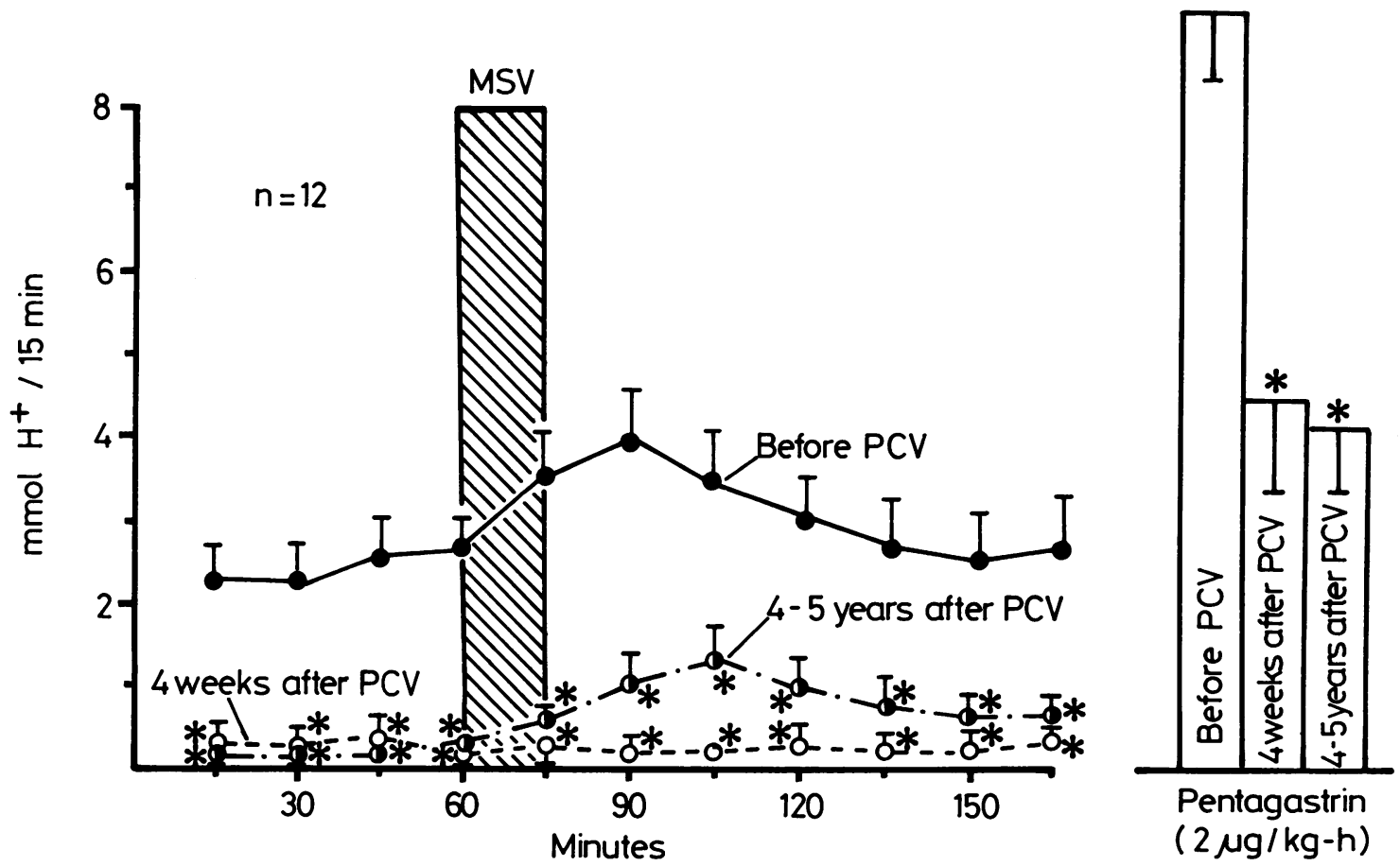

Fig. 2 Gastric acid outputs under basal conditions and after modified sham feeding (MSF) (performed during 15 min) and after infusion of pentagastrin $(2 \mu \mathrm{g} / \mathrm{kg} / \mathrm{h})$ in 12 duodenal ulcer patients before and 4 weeks and 4-5 years after parietal cell vagotomy $(P C V)$. Mean $\pm S E M$ of 12 tests on 12 patients. ${ }^{*}$ indicate significant $(p<0 \cdot 05)$ decrease below the control values obtained before parietal cell vagotomy $(P C V)$. 
than that achieved in the same patients before the truncal vagotomy. All the patients after truncal vagotomy had negative insulin test.

In the second group of duodenal ulcer patients studied before parietal cell vagotomy, the mean peak acid response to modified sham feeding expressed as per cent of the pentagastrin maximum was similar to that in previous group of patients submitted to truncal vagotomy. After the parietal cell vagotomy mean basal acid secretion was reduced by $85 \%$ (Fig. 2 ). Modified sham feeding was without significant influence on acid output while the pentagastrin infusion produced the mean peak response reaching about $57 \%$ of that achieved in these patients before the surgery. All these patients had negative insulin test.

After four to five years after parietal cell vagotomy, three of 12 patients had positive insulin test and all three patients showed a small but significant increase in gastric output in response to modified sham feeding. Their pentagastrin induced maximal acid output was within similar value to that recorded soon after parietal cell vagotomy and reached about $68 \%$ of that recorded before the surgery.

Among 28 patients tested before the surgery, six showed an increased basal acid secretion as expressed by $\mathrm{BAO} / \mathrm{PAO}$ ratio greater than $0 \cdot 30$. In these six subjects, the $\mathrm{BAO} / \mathrm{SAO}$ ratio tended to reach higher value $(0.54 \pm 0 \cdot 06)$ compared with that in the remaining 22 patients $(0 \cdot 33 \pm 0 \cdot 05)$ with decreased basal acid secretion (BAO/PAO ratio smaller than (0.30). The increment over basal in acid response to modified sham feeding in these six patients with higher basal secretion was not significantly different from that in the remaining 22 patients with normal or reduced basal secretion (Fig. 3).

No significant correlation was found between the ratio of $\mathrm{BAO} / \mathrm{PAO}$ and $\mathrm{SAO}-\mathrm{BAO}$.

EFFECTS OF TRUNCAL VAGOTOMY AND PARIETAL CEIL VAGOTOMY ON PLASMA GASTRIN AND

PANCREATIC POLYPEPTIDE LEVELS

Mean basal value of gastrin in patients before truncal vagotomy was about $77 \pm 10 \mathrm{pM}$ and modified sham feeding failed to significantly affect plasma gastrin concentrations. After truncal vagotomy the mean basal gastrin achieved significantly higher values than before surgery but modified sham feeding again did not significantly change plasma gastrin concentration and these results have been omitted.

In the second group of duodenal ulcer patients submitted to parietal cell vagotomy the mean basal gastrin concentration was similar before and after surgery and again modified sham feeding did not cause any significant alteration in plasma gastrin
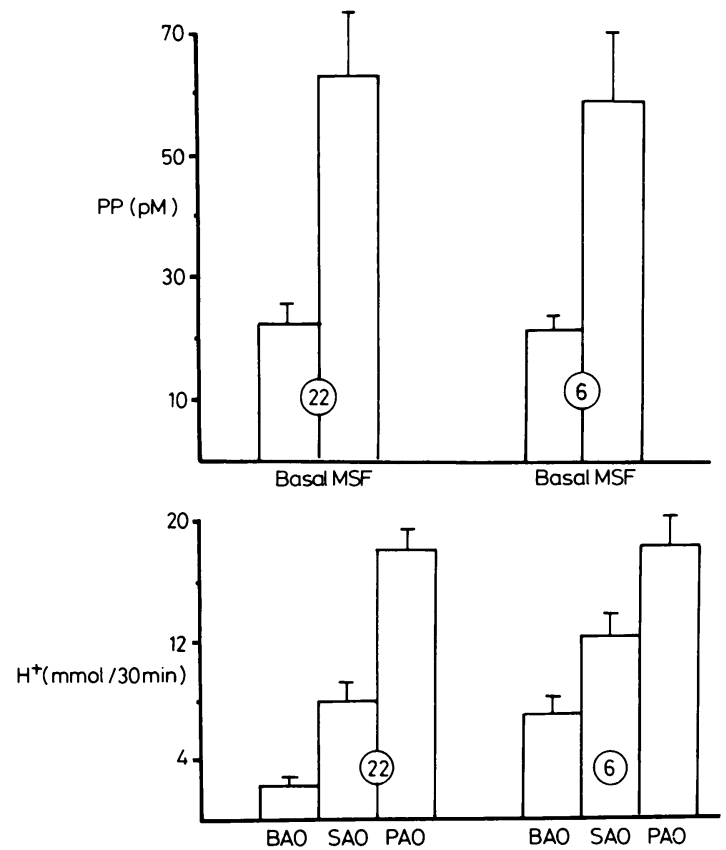

Fig. 3 Mean ( $\pm S E M)$ of basal and modified sham feeding $(M S F)$-induced peak plasma pancreatic polypeptide $(P P)$ levels in 22 duodenal-ulcer patients with low BAO/PAO ratio (less than $0 \cdot 3)$ and in 6 patients with high ratio $(0 \cdot 3$ or higher) (upper panel) and mean ( $\pm S E M)$ of basal $(B A O)$ acid secretion and of peak acid response to modified sham feeding $(M S F)(S A O)$ and pentagastrin $(P A O)$ in 22 patients with low and in 6 patients with high $B A O / P A O$ ratio (lower panel).

concentration before nor after the surgery. In these patients examined four to five years later, modified sham feeding was also without significant influence on plasma gastrin concentrations.

Basal plasma concentration of pancreatic polypeptide in patients before truncal vagotomy averaged $19 \pm 4 \mathrm{pM}$ and modified sham feeding resulted in an immediate and marked rise in pancreatic polypeptide seen in all 28 patients tested and reaching about $53 \pm 14$ pM within $7 \cdot 5$ minutes and a peak of $70 \pm 18$ pM within 15 minutes after the start of modified sham feeding (Fig. 4).

Plasma pancreatic polypeptide tended to decline at the end of tests - that is, about 105 minutes after modified sham feeding to the level not significantly different from the initial basal value. After truncal vagotomy, the basal pancreatic polypeptide value averaged $14 \pm 3.7 \mathrm{pM}$ and no significant change in plasma pancreatic polypeptide was observed during or after modified sham feeding in these patients. No significant difference was found in the increments in pancreatic polypeptide level after modified sham feeding among the patients with increased and 


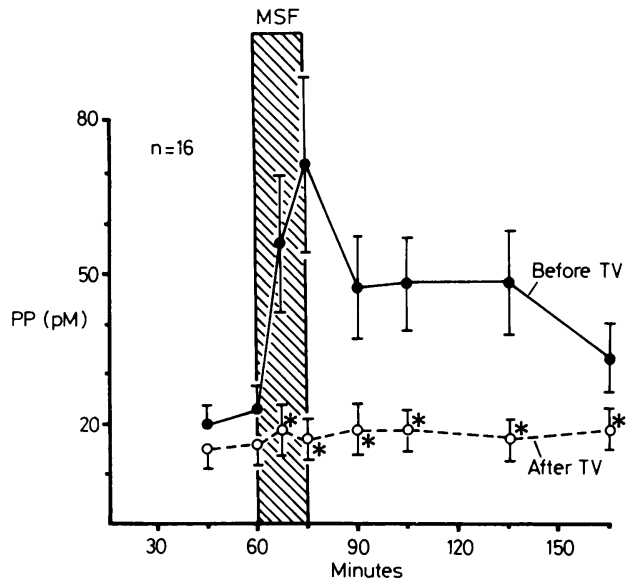

Fig. 4 Mean $\pm S E M$ of plasma pancreatic polypeptide (PP) concentrations under basal conditions and after modified sham feeding (MSF) in 16 duodenal ulcer patients before truncal vagotomy (TV). * indicate significant $(p<0 \cdot 05)$ decrease below the control value obtained before vagotomy.

reduced basal gastric acid secretion (Fig. 3). No significant correlation was seen between the increment of acid output in response to modified sham feeding (SAO-BAO) and the increment in plasma pancreatic polypeptide level after modified sham feeding and these results have not been included.

Basal values and incremental increase $(16 \pm 3 \cdot 7$ $\mathrm{pM}$ ) in plasma pancreatic polypeptide after modified sham feeding in second group of 12 patients before parietal cell vagotomy were similar to other patients before truncal vagotomy. After parietal cell vagotomy, basal pancreatic polypeptide values were not significantly altered $(20 \pm 2 \cdot 3 \mathrm{pM})$ but an average rise in plasma pancreatic polypeptide response to modified sham feeding was smaller $(5 \pm 1.3 \mathrm{pM})$ and observed only in seven of 12 patients tested (Fig. 5).

Four to five years later, basal pancreatic polypeptide values $(22 \pm 4.3 \mathrm{pM})$ were similar to those recorded before parietal cell vagotomy and modified sham feeding caused a significant increment $(20 \cdot 1 \pm$ $2.9 \mathrm{pM})$ seen in all subjects tested. The plasma pancreatic polypeptide value reached the peak within 15 minutes of modified sham feeding and then showed a tendency to decline towards the basal value.

\section{Discussion}

This study confirms that physiological vagal excitation induced by sham feeding in duodenal ulcer patients results in a potent gastric acid secretion accompanied by a marked increment in plasma pancreatic polypeptide and shows that truncal vagotomy abolishes completely gastric acid and pan- creatic polypeptide responses to modified sham feeding while parietal cell vagotomy abolishes gastric acid secretion but only temporarily impairs the pancreatic polypeptide responses to modified sham feeding.

The role of increased vagal activity in the pathogenesis of the acid secretory abnormalities in duodenal ulcer disease has been a subject of interest for many years. Feldman et al" suggested that the increase in basal acid output in some duodenal ulcer patients may be secondary to high vagal activity because in these patients the ratio of basal acid output to peak pentagastrin stimulated acid output was high $(0.3$ or greater $)$ and sham feeding failed to increase acid secretion above basal level. The hypothesis of high vagal activity as determined by a lack of gastric acid response to sham feeding in duodenal ulcer patients with the $\mathrm{BAO} / \mathrm{PAO}$ ratio greater than $0 \cdot 3$ was initially based on the observations obtained only from four patients." Kohn et al recently confirmed this hypothesis on a group of nine duodenal ulcer patients with basal hypersecretion who did not show any increase in acid secretion in response to sham feeding as opposed to 19 other patients with low basal secretion who showed a usual marked rise in acid secretion in response to modified sham feeding. They also observed a negative correlation between basal acid output, expressed as the percentage of peak pentagastrin induced acid output $(\mathrm{BAO} / \mathrm{PAO})$ and the modified sham feeding-induced increment in acid output over basal level (SAO-BAO).

In our present study including 28 duodenal ulcer patients submitted to surgery because of previous

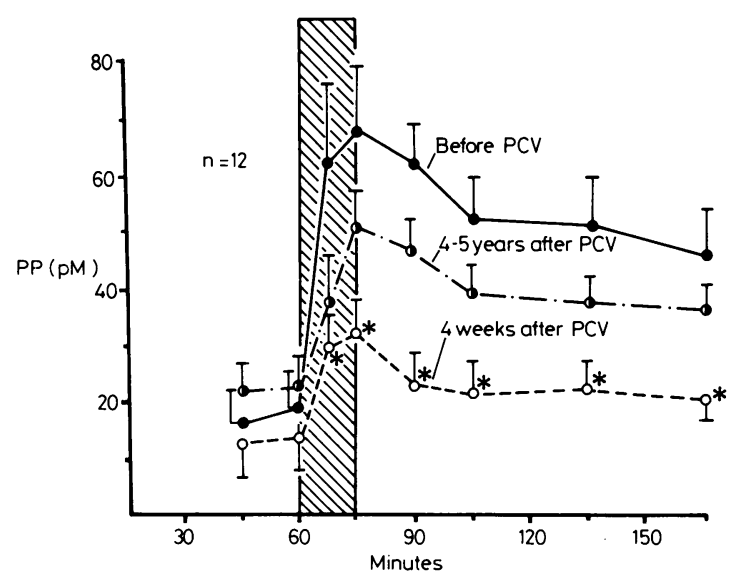

Fig. 5 Mean ( $\pm S E M)$ of plasma pancreatic polypeptide (PP) concentrations under basal conditions and after modified sham feeding (MSF) in 12 duodenal ulcer patients before parietal cell vagotomy $(P C V)$ and 4 weeks and 4-5 years after parietal cell vagotomy $(P C V) .{ }^{*}$ indicate significant $(p<0 \cdot 05)$ decrease below the control values obtained before parietal cell vagotomy $(P C V)$. 
ulcer complications and/or poor response to medical therapy, six of these patients exhibited high basal acid secretion as expressed by $\mathrm{BAO} / \mathrm{PAO}$ ratio greater than $0 \cdot 30$. All these patients, however, responded to modified sham feeding with an increase in acid output over basal level. Although the BAO/ SAO ratio in these six patients tended to be higher $(0 \cdot 54 \pm 0 \cdot 05)$ than in the remaining 22 patients $(0 \cdot 33 \pm$ 0.05 ) no significant correlation was found between basal output and the modified sham feeding-induced increment in acid output over basal level in the patients studied. Thus, we were unable to confirm the claims of previous reports ${ }^{17}$ that duodenal ulcer patients with high basal acid secretion do not respond to modified sham feeding, presumably because of initial high basal vagal activity. In fact, the increment over basal in response to modified sham feeding in our six patients with high basal secretion was not significantly different from that in remaining 22 patients with normal or low basal secretion. These results are in agreement with original findings of Knutson and Olbe ${ }^{17}$ who conducted a comparable study on 20 duodenal ulcer patients and found that seven with $\mathrm{BAO} / \mathrm{PAO}$ greater than 0.3 had acid increments after adequate sham feeding $(7 \cdot 0 \mathrm{mmol} /$ $30 \mathrm{~min}$ ) similar to those in the remaining 13 with lower $\mathrm{BAO} / \mathrm{PAO}(7 \cdot 1 \mathrm{mmol} / 30 \mathrm{~min})$. It appears, therefore, that just a lack of response to sham feeding in patients with increased $\mathrm{BAO} / \mathrm{PAO}$ ratio may not be an adequate method for testing vagal 'tone'. ${ }^{\text {' }}$

Gastric acid response to physiological vagal excitation by modified sham feeding was found in this and other studies to be accompanied by a marked and significant rise in plasma concentrations of pancreatic polypeptide. ${ }^{13+891213}$ In our study all 28 patients tested show a significant increase in plasma pancreatic polypeptide either during of after sham feeding. A significant rise in plasma pancreatic polypeptide was observed within 7.5 minutes and the mean peak occurred within 15 minutes after the start of modified sham feeding. Plasma pancreatic polypeptide then tended to decline but a significant increase in plasma pancreatic polypeptide over basal level was seen throughout the period of increased gastric acid secretory response to modified sham feeding. As in previous studies" no significant correlation was found between the increment in plasma pancreatic polypeptide concentration and the increase in acid secretion in response to modified sham feeding. Unlike a previous study, ${ }^{7}$ patients with higher $\mathrm{BAO} / \mathrm{PAO}$ ratio showed similar rise in pancreatic polypeptide to that in patients with low $\mathrm{BAO} / \mathrm{PAO}$. These results question the reliability of pancreatic polypeptide release as an independent indicator of vagal activation of the parietal cells. The pancreatic polypeptide response to modified sham feeding, however, appears to be totally dependent upon the intact vagal nerve supply to the pancreas." Our data show that truncal vagotomy abolishes plasma pancreatic polypeptide and gastric acid responses to modified sham feeding and are in agreement with previous reports. ${ }^{3 \% \text { : }}$

Previous studies show that selective gastric vagotomy also eliminated both gastric acid and pancreatic polypeptide responses to vagal stimulation by insulin hypoglycaemia. ${ }^{13}$ This has been explained by saying that the head of the pancreas, which is the major source of endogenous pancreatic polypeptide, is innervated by vagal fibres passing through the stomach and duodenum..$^{12}$ Such pancreatic innervation was originally proposed by Popielski ${ }^{14}$ in 1901 and more recently confirmed by anatomical and electrophysiological studies showing that, indeed, most of vagal fibres to the pancreas pass through vagal branches along the lesser curvature of the stomach across the pylorus.

This study provides evidence that the vagotomy of the oxyntic gland area not only eliminates gastric acid response to modified sham feeding, but also greatly reduces the pancreatic polypeptide response to vagal excitation. Shortly after parietal cell vagotomy, modified sham feeding failed to stimulate the release in pancreatic polypeptide in seven of 12 patients tested, and in others the pancreatic polypeptide response to modified sham feeding was significantly lower than in the same subjects before vagotomy. A similar reduction in pancreatic polypeptide response to sham feeding after parietal cell vagotomy was observed by Schwartz et $a l^{\prime \prime}$ and this has been attributed to the operative injury of the efferent vagal fibres to the pancreas. We found that the impairment of the vagal pancreatic innervation by parietal cell vagotomy was, however, not permanent. Patients with parietal cell vagotomy done four to five years earlier responded to modified sham feeding in a similar manner to that before surgery. It is of interest that in three of these 12 patients the insulin test was converted from negative shortly after parietal cell vagotomy to positive and all these insulin positive subjects showed a small but significant increase in gastric acid response to modified sham feeding. Thus, there was agreement between the results of insulin and modified sham feeding tests indicating that the secretory responses to vagal stimulation may sometimes recover, at least in part, after parietal cell vagotomy, possibly because of the regeneration of vagal fibres in the stomach. ${ }^{22}$ In spite of partial recovery of pancreatic polypeptide response to modified sham feeding and partial recovery of acid responses to modified sham feeding and insulin in our patients, the maximal response to pentagastrin remained reduced by about $40 \%$ immediately after 
parietal cell vagotomy. Thus a restitution of the pancreatic polypeptide response to vagal excitation after parietal cell vagotomy does not indicate an ineffective denervation of the target parietal cell area.

\section{References}

1 Świerczek JS, Konturek SJ, Tasler J, Jaworek J, Cieszkowski M. Pancreatic polypeptide and vagal stimulation of gastric and pancreatic secretion in dogs. Hepato-Gastroenterology 1981; 28: 206-9.

2 Knutson V, Olbe L. Gastric acid response to sham feeding before and after resection of antrum and duodenal bulb in duodenal ulcer patients. Scand $J$ Gastroenterol 1974; 9: 191-201.

3 Taylor IL, Feldman M, Richardson CT, Walsh JH. Gastric and cephalic stimulation of human pancreatic polypeptide release. Gastroenterology 1978; 75: 432-7.

4 Konturek SJ, Kwiecień N, Obtulowicz W, et al. Cephalic phase of gastric secretion in healthy subjects and duodenal ulcer patients: role of vagal innervation. Gut 1978; 20: 875-81.

5 Konturek SJ, Świerczek JS, Kwiecień N, et al. Gastric secretory and plasma hormonal responses to shamfeeding of varying duration in patients with duodenal ulcer. Gut 1981; 22: 1003-10.

6 Feldman M, Richardson CT, Fordtran JS. Effect of sham-feeding on gastric acid secretion in healthy subjects and duodenal ulcer patients: evidence for increased vagal tone in some ulcer patients. Gastroenterology 1980; 79: 796-800.

7 Kohn A, Annibale B, Suriano G, Severi C, Spinella S. Della Fave G. Gastric acid and pancreatic polypeptide responses to modified sham feeding: indication of an increased basal vagal tone in a subgroup of duodenal ulcer patients. Gut 1975; 26: 776-82.

8 Schwartz TW, Stenquist BO, Olbe L, Stadil F. Synchronous oscillations in the basal secretion of pancreatic polypeptide and gastric acid. Depression by cholinergic blockade of pancreatic polypeptide concentrations in plasma. Gastroenterology 1979; 76: 14-16.

9 Schwartz TW. Pancreatic polypeptide: a hormone under vagal control. Gastroenterology 1983; 85: 1411-25.

10) Schwartz TW, Rehfeld JF, Stadil F, Larssen LI, Moon N, Chance RE. Pancreatic polypeptide response to food in duodenal ulcer patients before and after truncal vagotomy. Lancet 1976; 1: 1102-5.

11 Taylor IL, Impicciatore M, Carter DC, Walsh JH. Effect of atropine and vagotomy on the pancreatic polypeptide response to a meal in dogs. Am J Physiol 1978; 235: E443-E447.

12 Poulsen J, Delikaris P, Lovgreen NA, Schwartz TW. Impaired pancreatic innervation after pyloric transection in dogs. Scand J Gastroenterol 1983; 18: 17-22.

13 Løvgren NA, Poulsen J, Schwartz TW. Impaired pancreatic innervation after selective gastric vagotomy. Scand J Gastroenterol 1981; 16: 811-6.

14 Gillespie G, Elder JB, Smith IS, et al. Analysis of basal acid secretion and its relation to the insulin response in normal and duodenal subjects. Gastroenterology 1972; 62: 903-11.

15 Saliciński PR. Iodination of proteins, glycoproteins and peptides using a solid phase oxidizing agent. 1,3,4,6-tetrachloro-3,6-diphenyl-glycoluril. Anal Biochem 1981; 117: 136-46.

16 Benett HPJ, Hudson AM, McMartin C, Purdon GE. Use of octadecylsilyl silica for the extraction and purification of peptides in biological samples. Biochem J 1977; 168: $9-13$.

17 Knutson U, Olbe L. Gastric acid response to shamfeeding before and after resection of antrum and duodenal bulb in duodenal ulcer patients. Scand $J$ Gastroenterol 1974; 9: 191-201.

18 Isenberg JI. 'Vagal tone' in duodenal ulcer and sham feeding as a test for completeness of vagotomy: Another point of view. Gastroenterology 1980; 79: 952-3.

19 Popielski C. Ueber das peripherische reflextorische Nervencentrum des Pancreas. Pfluegers Arch 1901; 86: 215-24

20 Gayet R, Guillaumie M. Sur le trajet des fibres excitatoire fournis an pancreas par les nerfs vagues. $C R$ Soc Biol (Paris) 1930; 103: 989-94.

21 Schwartz TW, Stenquist B, Olbe L. Cephalic phase of pancreatic-polypeptide secretion studied by sham feeding in man. Scand J Gastroenterol 1979; 14: 313-20.

22 Johnston D, Wilkinson AR, Humphrey CS, et al. Serial studies of gastric secretion in patients after highly selective (parietal cell) vagotomy without a drainage procedure for duodenal ulcer. Gastroenterology 1973; 64: $12-21$.

23 Hirschowitz BI, Hutchinson GA. Long-term effects of highly selective vagotomy (HSV) in dogs on acid and pepsin secretion. Am J Dig Dis 1977; 22: 81-93. 